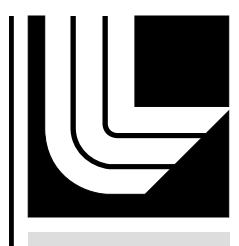

LAWRENCE LIVERMORE NATIONAL LABORATORY

Carbonate solutions for carbon capture: A summary

J. K. Stolaroff

October 15, 2013 
This document was prepared as an account of work sponsored by an agency of the United States government. Neither the United States government nor Lawrence Livermore National Security, LLC, nor any of their employees makes any warranty, expressed or implied, or assumes any legal liability or responsibility for the accuracy, completeness, or usefulness of any information, apparatus, product, or process disclosed, or represents that its use would not infringe privately owned rights. Reference herein to any specific commercial product, process, or service by trade name, trademark, manufacturer, or otherwise does not necessarily constitute or imply its endorsement, recommendation, or favoring by the United States government or Lawrence Livermore National Security, LLC. The views and opinions of authors expressed herein do not necessarily state or reflect those of the United States government or Lawrence Livermore National Security, LLC, and shall not be used for advertising or product endorsement purposes.

This work performed under the auspices of the U.S. Department of Energy by Lawrence Livermore National Laboratory under Contract DE-AC52-07NA27344. 


\title{
Carbonate solutions for carbon capture: a summary
}

\author{
Joshuah Stolaroff
}

November 17, 2011

\section{Background}

Potassium and sodium carbonate solutions have been studied and used for carbon capture applications since the early 20th century. They were first used to capture carbon dioxide for dry ice manufacturing, but were later supplanted by amine solutions (such as monoethanolamine, MEA) because of the faster reaction rate of amine solutions (Knuutila et al., 2009a). The use of carbonate solutions for other applications, however, has persisted to present day. In particular, the Benfield process (a.k.a the hot potassium carbonate process, or "hot pot") is widely used for the purification of natural gas, synthesis gas (from coal gasification), town gas, and other gases (Kohl and Nielsen, 1997).

Like all carbonate-based capture systems, the Benfield process relies on the reversible conversion of dissolved $\mathrm{CO}_{2}$ and carbonate $\left(\mathrm{CO}_{3}^{2-}\right)$ to bicarbonate $\left(\mathrm{HCO}_{3}^{-}\right)$:

$$
\mathrm{CO}_{3}^{2-}+\mathrm{CO}_{2}+\mathrm{H}_{2} \mathrm{O} \Longleftrightarrow 2 \mathrm{HCO}_{3}^{-}
$$

Typically, "promoters" are also added to speed the kinetics of $\mathrm{CO}_{2}$ absorption, including monoethanolamine (MEA) and other amines, glycine, and arsenius oxide (Kohl and Nielsen, 1997).

Most carbon capture schemes operate primarily in a temperature swing configuration: $\mathrm{CO}_{2}$ is absorbed at a low temperature (where the solubility of $\mathrm{CO}_{2}$ is high) and desorbed at a high temperature (where the solubility is low). In contrast, the Benfield process operates primarily with a pressure swing. $\mathrm{CO}_{2}$ is absorbed from a high-pressure gas stream $(\sim 20$ atm $)$ and desorbed at or near atmospheric pressure at roughly the same temperature. Desorption is aided by steam stripping, which further lowers the $\mathrm{CO}_{2}$ partial pressure during desorption. Because a hot solution is used for both absorption and desorption $\left(\approx 100^{\circ} \mathrm{C}\right)$, there is no need for a heat exchanger between the absorbing column ("absorber") and the desorbing column ("regenerator" or "stripper"). The other advantages of a high temperature in the absorber are faster kinetics (requiring a smaller absorber) and higher solubility of bicarbonate salts (more concentrated solutions). The disadvantage of the high temperature in the absorber is a lower equilibrium solubility of $\mathrm{CO}_{2}$ in the solution, which limits the purity of gas that can be achieved and requires a pressurized feed gas. This is partly offset by a "split stream" configuration, where a portion of the lean solution is cooled and added to the top of the absorbing column. The cooled solution can then absorb a bit more of the $\mathrm{CO}_{2}$ from the feed gas before it exits the top of the absorber. A process diagram is shown in Figure 1. Still, the high pressure requirement makes the conventional process unsuitable for capture from power plants. The minimum $\mathrm{CO}_{2}$ partial pressure that can be handled by a commercial system is $210-345 \mathrm{kPa}(2.1-3.4$ atm) (Chapel and Mariz, 1999) which would require a flue gas pressurized to at least 14 atm.

In other processes, carbonate solutions have been used to remove the acid gases $\mathrm{H}_{2} \mathrm{~S}$ and $\mathrm{HCN}$ by similar reactions as for $\mathrm{CO}_{2}$ :

$$
\begin{gathered}
\mathrm{Na}_{2} \mathrm{CO}_{3}+\mathrm{H}_{2} \mathrm{~S} \Longleftrightarrow \mathrm{NaHCO}_{3}+\mathrm{NaHS} \\
\mathrm{Na}_{2} \mathrm{CO}_{3}+\mathrm{HCN} \Longleftrightarrow \mathrm{NaCN}+\mathrm{HaHCO}_{3}
\end{gathered}
$$

In the early 20th century, this was done with the Seaboard process. The $\mathrm{H}_{2} \mathrm{~S}$ was absorbed into sodium or potassium carbonate solution and then stripped out with air at atmospheric pressure. The Seaboard process was supplanted by the Vacuum Carbonate Process which works similarly, but strips the $\mathrm{H}_{2} \mathrm{~S}$ and $\mathrm{HCN}$ under vacuum in steam, providing concentrated byproducts which can be further utilized. Vacuum carbonate systems are still used in some coke oven installations (Kohl and Nielsen, 1997).

One may ask, as long as we are adding and removing $\mathrm{CO}_{2}$ from potassium salts, why not swing from potassium bicarbonate all the way to potassium hydroxide? It would double the capacity of the solvent, and 


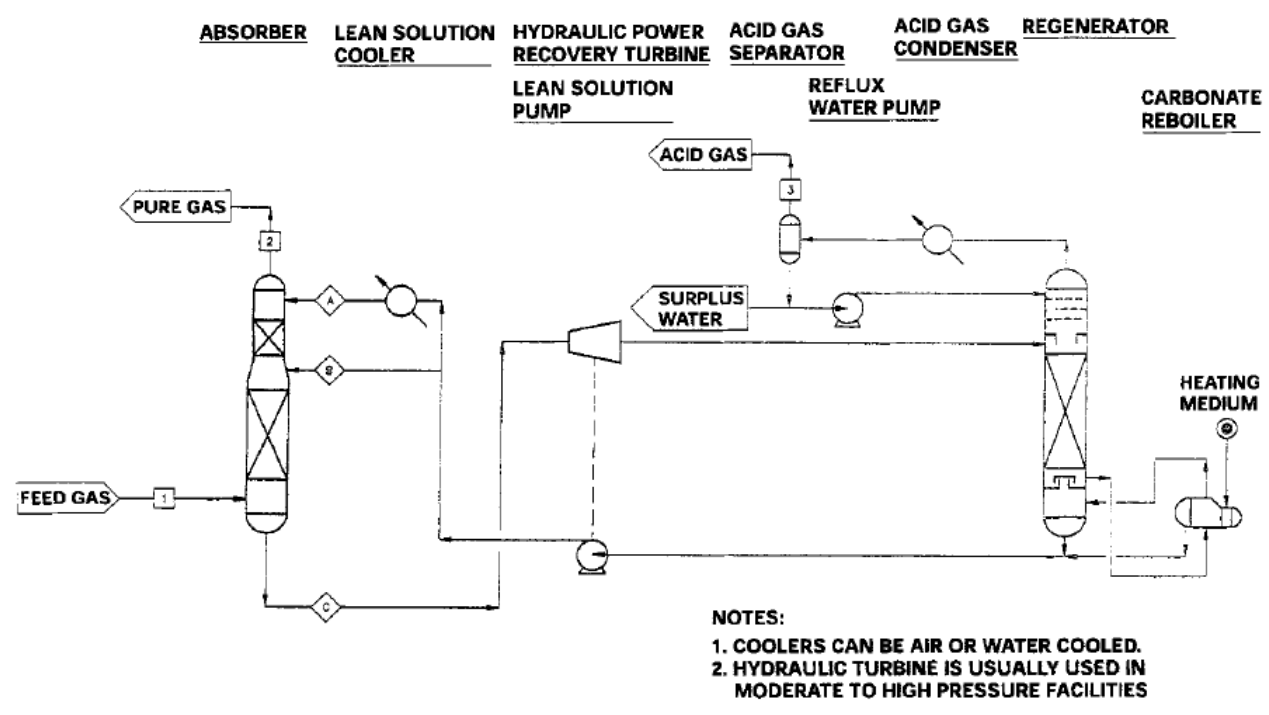

Figure 1: Flow diagram of hot potassium carbonate process for the absorption of $\mathrm{CO}_{2}$, split-stream configuration. $\mathrm{A}=$ cooled lean solution; $6=$ main lean solution stream: $\mathrm{C}=$ rich solution; $1=$ feed gas; $2=$ purified gas; 3 = acid gas. Source: Kohl and Nielsen (1997).

\begin{tabular}{lc}
\hline Solvent & Cost $\left[\$ /\right.$ mol- $-\mathrm{CO}_{2}$ capture capacity $]$ \\
\hline $\mathrm{MEA}$ & 0.544 \\
$\mathrm{Na}_{2} \mathrm{CO}_{3}$ ("Soda Ash") & 0.033 \\
$\mathrm{~K}_{2} \mathrm{CO}_{3}$ (as K $\mathrm{K}_{2} \mathrm{O}$, "Potash") & 0.044 \\
\hline
\end{tabular}

Table 1: Comparison of solvent costs. Carbonate capacities assume an average swing (rich loading-lean loading) of 33\%. Data from Abanades et al. (2004).

the high pH of hydroxide-carbonate mixtures would speed the kinetics of absorption. Indeed, hydroxidebased systems have been proposed for atmospheric carbon capture and used in various industrial processes historically. The primary drawback is that $\mathrm{KOH}$ and $\mathrm{NaOH}$ are not readily recoverable with a mild thermal or pressure swing, as are $\mathrm{K}_{2} \mathrm{CO}_{3}$ and $\mathrm{Na}_{2} \mathrm{CO}_{3}$. An additional chemical loop is required to recover the hydroxides, adding capital cost and energy requirements.

\section{Carbonates for capture from power plants}

Carbonate salts have several features that make them desirable for large-scale carbon capture and sequestration from power plants:

1. They are environmentally benign, especially compared with current commercial alternatives, such as MEA and piperazine.

2. They are inexpensive (see Table 1) and available in large quantities.

3. They are nonvolatile and resistant to degradation.

4. They have a low binding energy with $\mathrm{CO}_{2}$, providing at least the promise of a more energy-efficient capture system than current commercial alternatives.

Much of the recent research on carbonates for carbon capture from power plants focuses on a "dry" process, using solid sodium carbonate (Liang et al., 2004) or using solid supports functionalized with carbonate groups (Nelson et al., 2009; Zhao et al., 2009; Lee and Kim, 2007). The processes use steam pre-treatment or moisture in the flue gas to provide the water needed in Reaction 1 . However, aqueous systems have also received attention.

Kothandaraman et al. (2009) use ASPEN to model a capture system similar to the Benfield process and compare it to an MEA-based system for capture from coal and natural-gas power plants. They describe a 
number of process scenarios where the carbonate system has significantly lower reboiler duty (that is, heat required by the stripper) than the MEA system (the lowest reported duty is $2650 \mathrm{~kJ} / \mathrm{kg}-\mathrm{CO}_{2}$ for carbonates and $4152 \mathrm{~kJ} / \mathrm{kg}$ for MEA). However, the carbonate system that they simulate operates on high-pressure flue gas (15 atm), which is characteristic of the Benfield process. It appears that the energy to compress the flue gas (or the energy lost from not de-compressing it) was not taken into account. The authors fail to offer any general conclusions, other than that the carbonate system is especially useful for capture from a pressurized gas stream, such as from an Integrated Gasification Combined Cycle (IGCC) plant.

$\mathrm{Lu}$ et al. (2011) propose a capture system based on potassium carbonate catalyzed with carbonic anhydrase. In their system, the loaded carbonate solution is regenerated at relatively low temperature $\left(50-70^{\circ} \mathrm{C}\right)$ and under vacuum. They find that use of their system "could result in 20-35\% lower overall energy consumption" compared with an MEA-based system.

Cullinane and Rochelle (2004) studied the properties of potassium carbonate solutions promoted by piperazine. In a follow-up paper, Oyenekan and Rochelle (2006) used an ASPEN model to estimate the energy requirements of a potassium carbonate / piperazine capture system and an MEA-based capture system. Although they did not offer general conclusions about the overall fitness of carbonate-based capture, they concluded that a vacuum stripper configuration is the most energy-efficient for the carbonate solution, while a multi-pressure configuration is preferable for solvents with higher binding energy with $\mathrm{CO}_{2}$, such as MEA.

One potential benefit of carbonate-based capture is the simultaneous treatment of co-pollutants. For example, in natural gas purification, the Benfield process is used to capture both $\mathrm{CO}_{2}$ and $\mathrm{H}_{2} \mathrm{~S}$. Wappel et al. (2009) consider the possibility of using potassium carbonate to absorb $\mathrm{SO}_{2}$ and $\mathrm{CO}_{2}$ from flue gas in the same unit, which may significantly reduce the total cost of gas treatment compared with separate systems. Their measurements indicate that the solution preferentially absorbs $\mathrm{SO}_{2}$, increasing the equilibrium partial pressure of $\mathrm{CO}_{2}$ compared with a system free of $\mathrm{SO}_{2}$. They do not offer conclusions about the viability of the scheme, however.

Knuutila et al. (2009a) assess the feasibility of a capture system based on sodium carbonate slurry (a sodium carbonate solution where precipitate is allowed to form). They use the phase-equilibria software ChemCAD to model capture systems integrated with a condensing coal power plant and with a coal-fired combined heat and power station. They find that the reboiler duty in the carbonate system is $3200 \mathrm{~kJ} / \mathrm{kg}$ $\mathrm{CO}_{2}$, compared with literature values for MEA of $3800 \mathrm{~kJ} / \mathrm{kg}$. Similarly, they find the carbonate-based capture system reduces the power plant thermal efficiency from $39 \%$ with no capture to $30 \%$, whereas the efficiency penalty for MEA-based capture in the literature ranges from 11-15 percentage points. They did not consider the capital cost or practical details of a slurry-based absorber. They state, "The main drawback [of a sodium carbonate capture system] will be the slow transfer kinetics, leading to the need for a larger absorption tower." Knuutila and co-workers went on to publish four more thorough papers on the kinetics, equilibria, and physical properties of carbonate solutions, in each case making new physical measurements and reviewing literature values (Knuutila et al., 2009b, 2010a,c,b). At least as indicated by their willingness

to revisit decades-standing measurements and kinetic models, Knuutila and co-workers appear convinced of the viability of carbonate-based capture.

\section{Physical Properties}

Physical properties of carbonate solutions vary along three dimensions important to the capture process:

1. Initial carbonate concentration. This is usually expressed as weight percent (wt\%) when all of the salt is in the carbonate form $\left(\mathrm{Na}_{2} \mathrm{CO}_{3}\right.$ or $\left.\mathrm{K}_{2} \mathrm{CO}_{3}\right)$, which is to say, $0 \%$ loading. It may also be expressed in molal ( $\mathrm{m}$, mol $\mathrm{Na}_{2} \mathrm{CO}_{3}$ or $\mathrm{K}_{2} \mathrm{CO}_{3}$ per liter of water) or molal of cation $\left(\mathrm{m} \mathrm{K}^{+}\right.$or $\mathrm{Na}^{+}$), which is nice because it stays unambiguously constant as the solution is loaded, but sometimes confusing because the molality of cation is twice the molality of carbonate. Concentrations in M (mol carbonate per L of solution) are usually required in chemical expressions. Weight percent and molality can be readily inter-converted, but care should be taken with molarity since the solution density is often significantly different from water.

2. Loading or "conversion to bicarbonate." $\mathrm{As}^{\mathrm{CO}_{2}}$ is added to the solution, $\mathrm{CO}_{3}^{2-}$ converts to $\mathrm{HCO}_{3}^{-}$by Reaction 1 . The fractional loading or conversion to bicarbonate can be defined:

$$
\text { loading }=\frac{2 \cdot\left(\text { moles of total } \mathrm{CO}_{2}\right)}{\text { moles of cation }}-1
$$




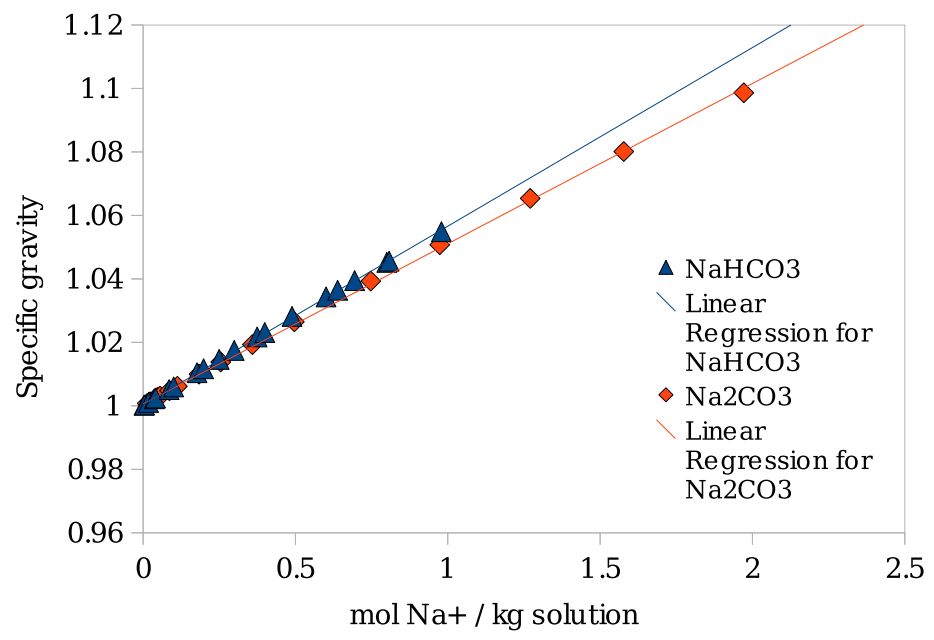

Figure 2: Density of sodium carbonate and bicarbonate solutions at $25^{\circ} \mathrm{C}$. Data from Hershey et al. (1983).

and is usually shown as a percent.

3. Temperature. Since a capture system will most likely be based on a temperature swing, properties across at least the temperature range $40-120^{\circ} \mathrm{C}$ are important.

Concentrated potassium carbonate solutions have been measured extensively in connection with the Benfield process, although much of the data is confined to the temperature range of interest for that process. Properties of sodium and potassium carbonate solutions of varying concentrations and at varying temperature are available in handbooks and in the general literature, though usually not across all three dimensions. Some of the properties are summarized below.

\section{Density}

Densities of $\mathrm{Na}_{2} \mathrm{CO}_{3}$ and $\mathrm{K}_{2} \mathrm{CO}_{3}$ solutions are available from a number of sources, most notably Knuutila et al. (2010b), who provide densities for sodium solutions up to $30 \mathrm{wt} \%$ and potassium solutions up to 50 wt $\%$ in the temperature range $25-80^{\circ} \mathrm{C}$. Knuutila et al. also provide a review of previous work. Densities of loaded solutions (i.e., bicarbonate solutions or carbonate and bicarbonate mixtures) are harder to come by. Hershey et al. (1983) measured densities of pure sodium bicarbonate solutions, however only up to $1 \mathrm{~mol} / \mathrm{kg}$ and $45^{\circ} \mathrm{C}$. They also fit a 12-parameter model to their data which can be used to calculate density over the temperature and concentration ranges they measured. Figure 2 shows some of the data. At least up to the $1 \mathrm{~m}$ concentration measured, loading of the solution (conversion to bicarbonate) appears to increase the density only slightly. Poling et al. (2008) also provides the density of pure potassium bicarbonate solutions up to $10 \mathrm{wt} \%$ at $15{ }^{\circ} \mathrm{C}$, and Knovel (2008) provides the density of $8 \mathrm{wt} \%$ sodium bicarbonate at $18^{\circ} \mathrm{C}$.

\section{Viscosity}

Figure 3 shows the viscosity of concentrated $\mathrm{K}_{2} \mathrm{CO}_{3}$ solutions for a range of temperatures. Additionally, Correla and Kestlin (1980) provide viscosity of sodium and potassium carbonate solutions in the temperature range $20-90^{\circ} \mathrm{C}$ up to $1.7 \mathrm{~m}$ for sodium and $2.5 \mathrm{~m}$ for potassium. Knuutila et al. (2010c) plot the viscosity, relative to water, of $\mathrm{Na}_{2} \mathrm{CO}_{3}$ and $\mathrm{K}_{2} \mathrm{CO}_{3}$ solutions up to 3 and $5.5 \mathrm{~m}$, respectively, at $50^{\circ} \mathrm{C}$. From their plot, the sodium solutions are somewhat more viscous - almost a factor of two at the same molarity. I have not found a source for the viscosity of loaded solutions.

\section{Solid solubility}

Higher concentrations of sodium and potassium carbonates are soluble at higher temperatures. Also, bicarbonate salts are less soluble than carbonate salts. Thus, precipitates tend to form as a solution becomes 


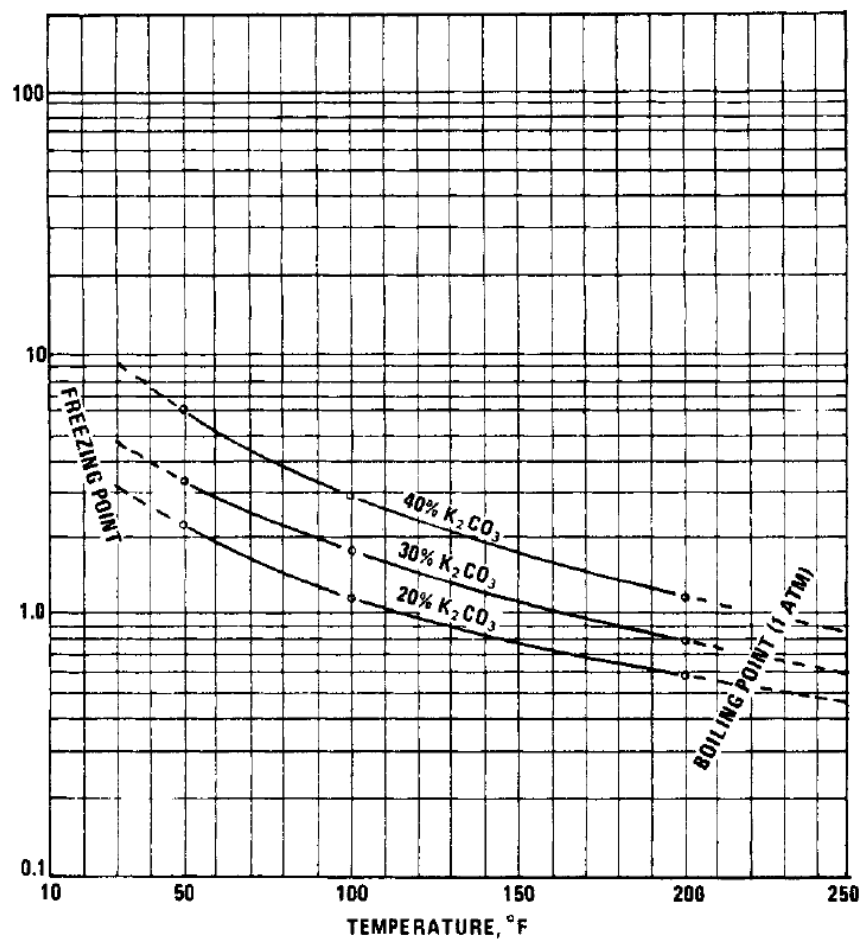

Figure 3: Viscosity of potassium carbonate solutions. Source: Kohl and Nielsen (1997), cited there as Allied Chemical Corporation, 1961.

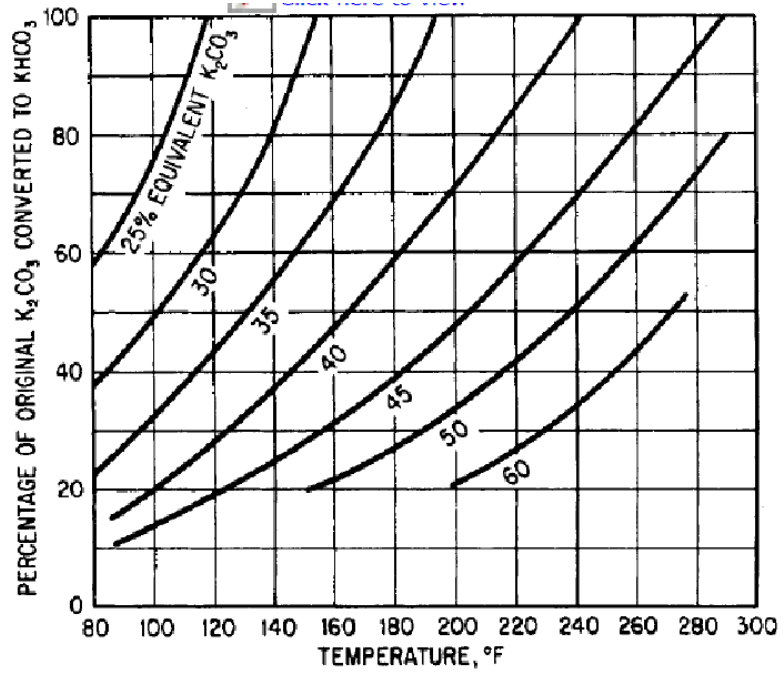

Figure 4: Solubility of $\mathrm{K}_{2} \mathrm{CO}_{3}+\mathrm{KHCO}_{3}$ as a function of temperature. Lines represent solubility limits for given salt concentrations (in wt\%). Taken from Kohl and Nielsen (1997). 


\begin{tabular}{ccc}
\hline Temp. $\left[{ }^{\circ} \mathrm{C}\right]$ & $K_{V L E}$ for $20 \mathrm{wt} \%$ & $K_{V L E}$ for $30 \mathrm{wt} \%$ \\
\hline 70 & 0.042 & 0.058 \\
90 & 0.022 & 0.030 \\
110 & 0.013 & 0.017 \\
130 & 0.0086 & 0.011 \\
\hline
\end{tabular}

Table 2: Equilibrium constant values from Tosh et al. (1959) for Equation 2 for solutions of the given concentration. $K_{V L E}$ in $\frac{\mathrm{M}}{\mathrm{mmHg}}$.

more loaded with $\mathrm{CO}_{2}$ or drops in temperature. Traditionally, concentrations are avoided which form a precipitate in any part of a process. For this reason, potassium carbonates, which are more soluble than sodium, have been more popular in industrial applications. Although there are plenty of industrial processes which operate effectively on slurries (spray-based $\mathrm{SO}_{2}$ scrubbers for power plants being a prime example), the presence of precipitates severely limits the range of process options.

Figure 4 shows the solubility limits for the potassium system. Although I have not found a similar plot for sodium in the literature, we can calculate such limits with a geochemical model, which we have done or are in the process of doing.

\section{Vapor-liquid equilibrium (VLE)}

The "classic" source of VLE data for the potassium system is the U.S. Bureau of Mines study by Tosh et al. (1959), which they undertook in support of the Benfield process. They distill their measurements to a set of equilibrium constants that can be used with the equation:

$$
K_{V L E}=\frac{\left[\mathrm{KHCO}_{3}\right]^{2}}{\left[\mathrm{~K}_{2} \mathrm{CO}_{3}\right] P_{\mathrm{CO}_{2}}}
$$

with $P_{\mathrm{CO}_{2}}$ in $\mathrm{mm} \mathrm{Hg}$. Table 2 gives values of the constant.

Kamps et al. (2007) measure VLE data for potassium carbonate solutions in the temperature range 40$120^{\circ} \mathrm{C}$ and concentrations of 0.43 and $1.7 \mathrm{~m}$ (5.6 and $\left.19 \mathrm{wt} \%\right)$. They also incorporate data from Tosh et al. and provide Pitzer model parameters for the system.

Knuutila et al. (2010a) review literature and provide measurements on VLE of the sodium carbonate system in the temperature range $40-80^{\circ} \mathrm{C}$ and concentrations up to $12 \mathrm{wt} \%$. This goes higher in temperature than any of the previous work they reviewed except for Ellis (1959), which covers the range $120-195^{\circ} \mathrm{C}$, but only up to a concentration of $5 \mathrm{wt} \%$. There may be a gap in high-temperature, high-concentration sodium measurements. In which case, the limited interest may be due to the tendency of high-concentration sodium solutions to form precipitates.

\section{Chemistry and mass transfer}

Carbonate salts do not react with $\mathrm{CO}_{2}$ directly (as opposed to many amines, for example, which react directly to form carbamates), but rather act as a buffer, generally keeping the solution in the $\mathrm{pH}$ range 9-11 (Kohl and Nielsen, 1997). In this $\mathrm{pH}$ range (i.e., above about $\mathrm{pH} 8$ ), the dominant reaction with $\mathrm{CO}_{2}$ is:

$$
\mathrm{CO}_{2}(\mathrm{aq})+\mathrm{OH}^{-} \Longrightarrow \mathrm{HCO}_{3}^{-}
$$

with the reaction rate:

$$
R=k_{\mathrm{OH}}\left[\mathrm{OH}^{-}\right]\left[\mathrm{CO}_{2}(\mathrm{aq})\right]
$$

The concentration of salt and type of cation affects the reaction rate in three respects:

1. controlling the $\mathrm{pH} / \mathrm{OH}^{-}$concentration (the buffer effect)

2. changing the reaction rate through non-ideal ion-ion interactions (the activity effect), and

3. changing the $\mathrm{CO}_{2}(\mathrm{aq})$ concentration at the interface by changing the Henry's constant (the solubility affect, a.k.a., the "salting-out" effect). 


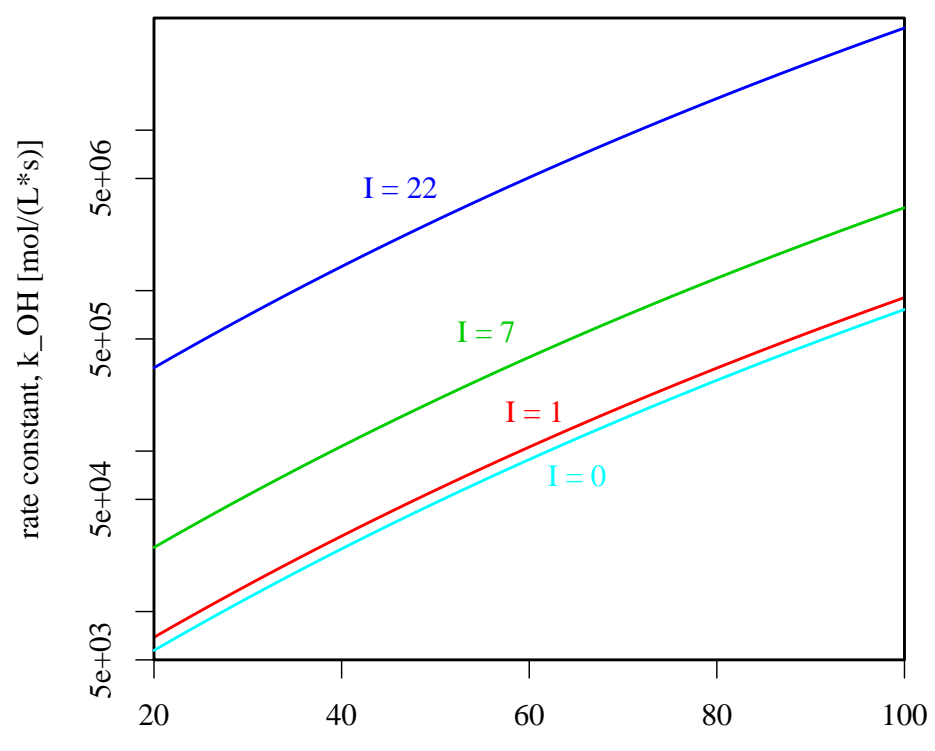

Temperature $[\mathrm{K}]$

Figure 5: Concentration-based rate constant, $k_{\mathrm{OH}}$, as a function of temperature and ionic strength, $I$, according to equation $5(I=\{1,7,22\})$ and Equation $6(I=0)$.

In addition, the concentration and type of cation determines the viscosity of the solution, which influences the diffusivity of $\mathrm{CO}_{2}$ in solution.

There are essentially two approaches to calculating reaction rates and mass transfer in carbonate systems. The traditional approach, the "concentration-based approach," is to use empirically-adjusted factors for the reaction constants (e.g., $k_{\mathrm{OH}}$ ), and Henry's constant. These depend on the ion concentrations and temperature of the solution, as does the diffusivity. Astarita et al. (1983) developed the following expression for the concentration-based, second-order rate constant (with $k_{\mathrm{OH}}$ in units $\mathrm{L} /(\mathrm{mol} \cdot \mathrm{s})$ ):

$$
\log \left(k_{\mathrm{OH}}\right)=13.635-2895 / T+0.08 I
$$

where $T$ is the temperature in $\mathrm{K}$, and $I$ is the ionic strength in M. Figure 5 plots this expression for a range of temperatures and several ionic strengths.

The second approach to reaction and mass transfer calculations is to use activity coefficients. The advantage of this approach is that the kinetic and equilibrium constants at infinite dilution (which are easier to come by than concentration-adjusted ones) can be used. The constants will not vary with solution composition, only with temperature. The disadvantage is that one has to calculate activity coefficients for high-ionic strength solutions (up to $I=22$ for $50 \mathrm{wt} \% \mathrm{~K}_{2} \mathrm{CO}_{3}$ ) where the friendlier activity models (e.g. Davies) are generally not valid. The "specific ion interaction theory" (SIT) model is sometimes used (e.g. Puxty and Rowland, 2011), but the Pitzer model is preferred, and is challenging for its complexity and many adjustable parameters which must be calibrated against empirical data. Using activity coefficients, however, is the more rigorous and modern approach. After combining their own measurements with some from the literature, Knuutila et al. (2010c) calculate this expression for the second-order kinetic constant at infinite dilution:

$$
k_{\mathrm{OH}}^{\infty}=4.65 \times 10^{13} e^{55586 /(R T)}
$$

with $T$ in $\mathrm{K}$ and $k_{\mathrm{OH}}^{\infty}$ in $\mathrm{L} /(\mathrm{mol} \cdot \mathrm{s})$. This constant can be used with the activity-based rate expression:

$$
R=k_{\mathrm{OH}}^{\infty}\left\{\mathrm{OH}^{-}\right\}\left\{\mathrm{CO}_{2}(\mathrm{aq})\right\}
$$

where the curly braces \{\} denote the activity of a species. Equation 6 is plotted in Figure 5 as " $I=0$ " and, as we would hope, virtually overlaps with Equation 5 for $I=0$. 


\section{Catalysts and rate enhancement}

In order to compare the reaction rates of multiple mechanisms, it is useful to define a "pseudo-first-order" rate constant, $k_{1}$, so that the conversion rate of $\mathrm{CO}_{2}$ is:

$$
R=k_{1}\left[\mathrm{CO}_{2}(\mathrm{aq})\right]
$$

For a carbonate solution, we can see from Equation 4 that:

$$
k_{1}=k_{\mathrm{OH}}\left[\mathrm{OH}^{-}\right]
$$

Note that we are making the approximation that the reverse of reaction 3 is much smaller than the forward reaction. This is decent assumption for a lean solution but will break down as the solution approaches saturation. Thus we may be overestimating the (uncatalyzed) $\mathrm{CO}_{2}$ absorption rate. However, we will retain this assumption for the almost magical simplicity that it yields.

Alternatively to the previous two equations, we have from Equation 7:

$$
\begin{gathered}
R=k_{1}^{\infty}\left\{\mathrm{CO}_{2}(\mathrm{aq})\right\} \\
k_{1}^{\infty}=k_{\mathrm{OH}}^{\infty}\left\{\mathrm{OH}^{-}\right\}
\end{gathered}
$$

The activity of $\mathrm{OH}^{-}$can be readily calculated from the $\mathrm{pH}$ of a solution by:

$$
K_{w}=\left\{\mathrm{H}^{+}\right\}\left\{\mathrm{OH}^{-}\right\} \Longrightarrow\left\{\mathrm{OH}^{-}\right\}=K_{w} / 10^{-\mathrm{pH}}
$$

A handy feature of carbonate solutions at this point is that they are good buffers. Buffers keep pH in a narrow range even against addition of an acid (like $\mathrm{CO}_{2}$ ). That is the very feature that makes them useful for carbon capture. Figure 6 shows the $\mathrm{pH}$ of several carbonate/bicarbonate solutions for a range of $\mathrm{CO}_{2}$ loading, as calculated by the CHESS software (van der Lee, 1998), based on the EQ3/6 chemical database (Woolery, 1992). Although the $\mathrm{pH}$ of pure $\mathrm{K}_{2} \mathrm{CO}_{3}$ solutions can be as high as 13 or more (Knuutila et al., 2010c), the $\mathrm{pH}$ of loaded solutions is much lower and tends to remain in a narrower range. Additionally, the working swing between lean and rich loading is likely to stay within the shallow middle of the $\mathrm{pH}$ curve. For reference, the loading range calculated by Knuutila et al. (2009a) for an absorber operating at 2 bar is 29-83\%. Based on the $\mathrm{CO}_{2}$ fugacity reported by CHESS and reasonable assumptions about an absorber operating at atmospheric pressure, my own guess about the working swing for the $30 \mathrm{wt} \% \mathrm{Na}_{2} \mathrm{CO}_{3}$ solution in Figure 6 is about $28-62 \%$.

The reaction rate in a carbonate solution depends on a good deal of adjustable parameters, including ion type, initial salt concentration, temperature, and $\mathrm{CO}_{2}$ loading, which all in turn should be optimized for the capture system. I must also give the caveat that CHESS does not use the rigorous Pitzer activity model (I have it configured for the "b-dot" model), and thus introduces some error. However, in the face of all this, I consider it a good assumption that the majority of $\mathrm{CO}_{2}$ absorption will be taking place below pH 10 and probably below $\mathrm{pH} 9.5$. With this in mind, it should be useful to calculate $k_{1}^{\infty}$ as a function of $\mathrm{pH}$. The results are shown in Figure 7. Note that the line for $25^{\circ} \mathrm{C}$ is directly comparable with our famous reaction rate vs. $\mathrm{pH}$ plot and, comfortingly, matches the hydroxide line drawn there.

When a "promoter" or catalyst is present, additional reactions can increase the conversion rate of $\mathrm{CO}_{2}(\mathrm{aq})$ above the lines drawn in Figure 7. For example, for direct reaction with a primary or secondary amine (Puxty and Rowland, 2011),

$$
\mathrm{R}_{1} \mathrm{R}_{2} \mathrm{NH}+\mathrm{CO}_{2} \Longrightarrow \mathrm{R}_{1} \mathrm{R}_{2} \mathrm{NCOO}^{-}+\mathrm{H}^{+}
$$

the pseudo-first-order rate constant becomes:

$$
k_{1, A m}=k_{1}+k_{a m}\left[\mathrm{R}_{1} \mathrm{R}_{2} \mathrm{NH}\right]
$$

In general, the action of promoters can be described by the series (Kohl and Nielsen, 1997):

$$
\begin{aligned}
\mathrm{CO}_{2}+\text { promoter } & \Longrightarrow \text { intermediate } \\
\text { intermediate }+\mathrm{OH}^{-} & \Longrightarrow \mathrm{HCO}_{3}^{-}+\text {promoter }
\end{aligned}
$$

When the second reaction is much faster than the first, as is the case for arsenious acid and hindered amines, then the promoter acts as a homogeneous catalyst. If the second reaction is relatively slow, then diffusion 


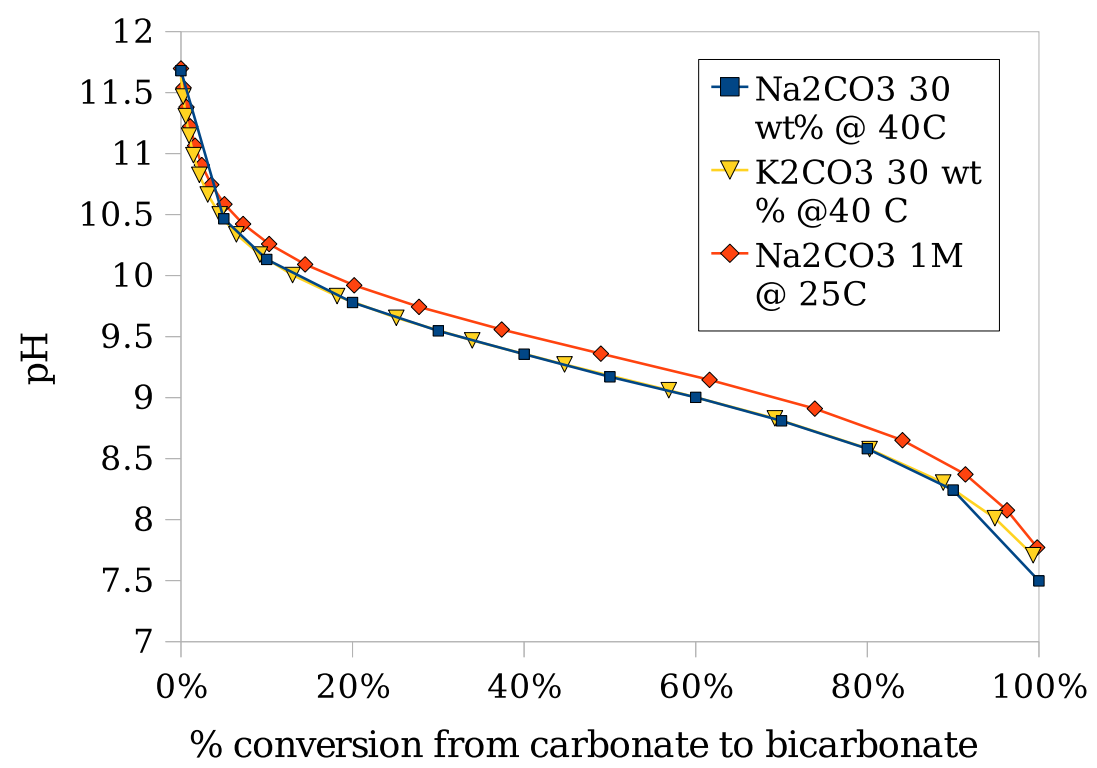

Figure 6: $\mathrm{pH}$ of several carbonate solutions vs $\mathrm{CO}_{2}$ loading.

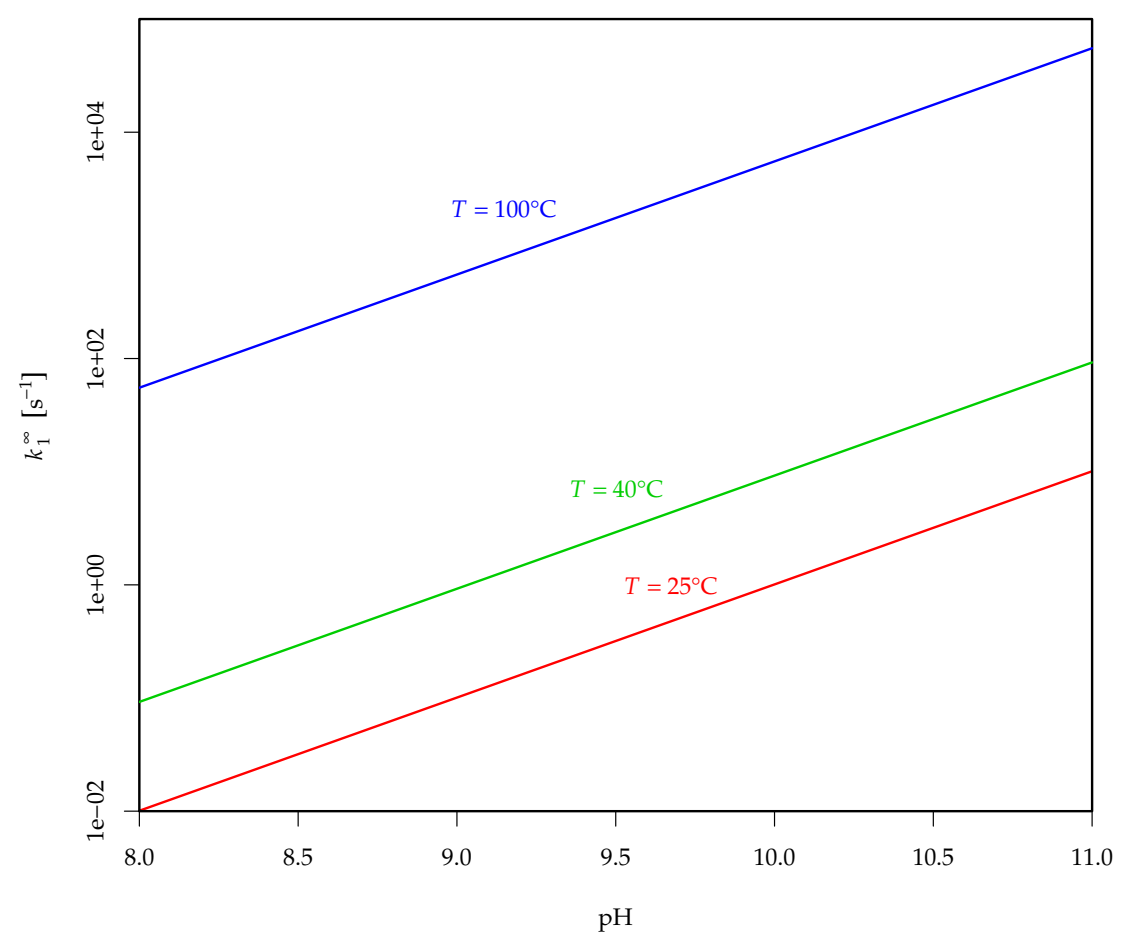

Figure 7: Activity-based, pseudo-first-order rate constant, $k_{1}^{\infty}$, as a function of $\mathrm{pH}$ and temperature. 
of the intermediate to the bulk solution can be a significant part of the mass transfer problem, as may be the case for unhindered amines at moderate temperatures (although this appears to be disputed) (Kohl and Nielsen, 1997).

For a catalyst like carbonic anhydrase and its mimics, the mechanism can be described by a similar series (with the catalyst represented by "Cat"):

$$
\begin{aligned}
\mathrm{CatOH}+\mathrm{CO}_{2}(\mathrm{aq}) & \Longrightarrow \mathrm{CatHCO}_{3} \\
\mathrm{CatHCO}_{3}+\mathrm{H}_{2} \mathrm{O} & \Longrightarrow \mathrm{CatOH}+\mathrm{H}^{+}+\mathrm{HCO}_{3}^{-}
\end{aligned}
$$

For carbonic anhydrase and the $\mathrm{Zn}(\mathrm{II})$ complex of 1,4,7,10-tetraazacyclododecane ("cyclen"), the second reaction is much faster than the first, so the reaction rate can be described by:

$$
\begin{aligned}
R_{c a t} & =k_{\text {cat }}[\mathrm{CatOH}]\left[\mathrm{CO}_{2}(\mathrm{aq})\right] \\
\Longrightarrow k_{1, \text { cat }} & =k_{1}+k_{\text {cat }}[\mathrm{CatOH}]
\end{aligned}
$$

Again, we are neglecting the reverse reaction, which would come into play at high loading or low $\mathrm{pH}$. We have also written the catalyst concentration, whereas to be fully consistent we should use the catalyst activity, but for the order-of-magnitude calculations that follow, this should not be serious problem. The third and final complication is that only the hydroxide complex of the catalyst is active and the catalyst itself is an acid. At a solution $\mathrm{pH}$ near or below the $\mathrm{p} K_{a}$ of the catalyst, much of the catalyst will be inactive and $R_{c a t}$ will be a function of $\mathrm{pH}$. The effective $k_{\text {cat }}$ can then be described by (Zhang and van Eldik, 1995):

$$
k_{c a t, e f f}=k_{c a t} \frac{K_{a}}{\left[H^{+}\right]+K_{a}}
$$

If the solution $\mathrm{pH}$ stays sufficiently above the $\mathrm{p} K_{a}$ of the catalyst then essentially all catalyst is active. This is a good assumption for cyclen above pH 9 (Zhang and van Eldik, 1995).

We now consider the concentration of catalyst required to enhance the reaction rate of a carbonate solution. The concentration required to double the uncatalyzed reaction rate is defined by:

$$
k_{c a t}[\mathrm{CatOH}]=k_{1}
$$

Figure 8 plots the results for several values of $k_{c a t}$. To achieve further enhancement of the reaction rate, it is fairly straightforward to extrapolate from these results. For example, to achieve a 100 times boost in reaction rate, multiple the concentration shown by 100 .

For comparison, Cullinane and Rochelle (2004) measured the mass-transfer enhancement from $0.6 \mathrm{M}$ piperazine added to $20 \mathrm{wt} \% \mathrm{~K}_{2} \mathrm{CO}_{3}$ as a promoter. Although their chemical-kinetic model for the mixture is considerably complex, they find that a pseudo-first-order model similar to Equation 10 describes most of the solutions well (except at low loading). Using their measured flux for a $20 \%$ loaded solution at $40^{\circ} \mathrm{C}$, we can back out a pseudo-first-order rate constant, which comes to about $6000 \mathrm{~s}^{-1}$. To make this figure comparable with our $\mathrm{pH}$ vs. rate plot, we have to adjust it to an amine concentration of $1 \mathrm{M}$ instead of 0.6 $\mathrm{M}$, which puts the rate at about $10^{4} \mathrm{~s}^{-1}$. More generally, they describe the enhancement by piperazine as about a factor of 10 in terms of flux, which, by Equation 10, is about a factor of 100 in terms of reaction rate. The enhanced flux, they find, is comparable to a solution of $7 \mathrm{~m}$ MEA.

\section{Mass transfer and penetration depth}

With the pseudo-first-order approximation for reaction rate, the mass transfer rate can be calculated with a relatively simple expression. Assuming a liquid film of thickness $l$ and negligible mass transfer resistance in the gas phase, the flux, $J_{\mathrm{CO}_{2}}$, across the interface is (Cussler, 1984):

$$
J_{\mathrm{CO}_{2}}=\left(P_{\mathrm{CO}_{2}}-P_{\mathrm{CO}_{2}}^{*}\right) H_{a p p} \sqrt{D_{\mathrm{CO}_{2}} k_{1}} \operatorname{coth}\left(l \cdot \sqrt{k_{1} / D_{\mathrm{CO}_{2}}}\right)
$$

where $P_{\mathrm{CO}_{2}}$ is the partial pressure of $\mathrm{CO}_{2}$ in the gas, $P_{\mathrm{CO}_{2}}^{*}$ is the partial pressure at equilibrium with the solution at the particular loading (the "backpressure"), $H_{a p p}$ is the "apparent" Henry's constant (adjusted for the solubility affect), $D_{\mathrm{CO}_{2}}$ is the diffusivity of $\mathrm{CO}_{2}$ in the solution and $k_{1}$ is the pseudo-first-order rate constant. 


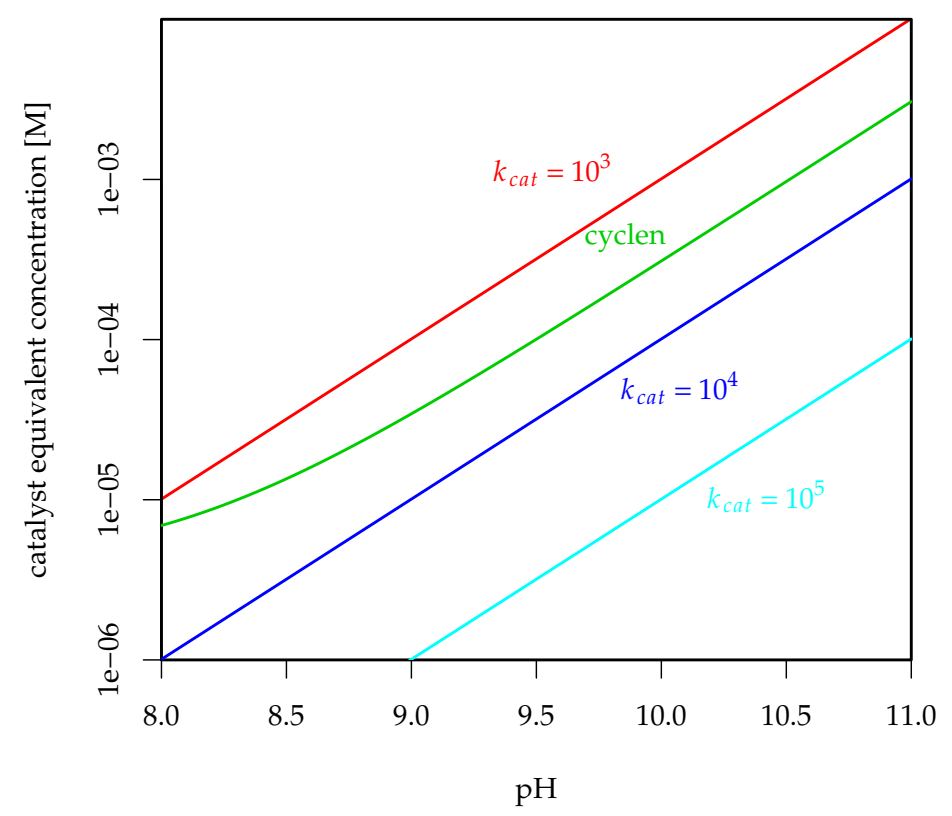

Figure 8: Concentration of catalyst required to double the reaction rate of a carbonate solution as a function of $\mathrm{pH}$ for several values of the catalyst reaction constant, $k_{\text {cat }}[\mathrm{L} /(\mathrm{mol} \cdot \mathrm{s})] . T=25^{\circ} \mathrm{C}$. "Cyclen" refers to the value of reaction constant for cyclen given by Zhang and van Eldik (1995), $k_{c a t}=3300$, adjusted by Equation 8 with $\mathrm{p} K_{a}=8.1$. The other lines are not adjusted for $\mathrm{p} K_{a}$ effects (i.e., I assumed a low $\mathrm{p} K_{a}$ ).

The reaction can be considered "pseudo-first-order" if the $\mathrm{OH}^{-}$concentration is much larger than $\mathrm{CO}_{2}(\mathrm{aq})$ and thus doesn't change much throughout the liquid film. This is a good assumption for concentrated carbonate solutions. If we further assume that the reaction rate $k_{1}$ is fast compared to the diffusion-based mass transfer rate $\left(D_{\mathrm{CO}_{2}} / l\right)$, then Equation 9 simplifies to (Cussler, 1984; Cullinane and Rochelle, 2004; Knuutila et al., 2010c):

$$
J_{\mathrm{CO}_{2}}=\left(P_{\mathrm{CO}_{2}}-P_{\mathrm{CO}_{2}}^{*}\right) H_{a p p} \sqrt{D_{\mathrm{CO}_{2}} k_{1}}
$$

That $k_{1}$ is fast is a good assumption for concentrated carbonate solutions (Knuutila et al., 2010c). Note that the mass transfer rate no longer depends on the film thickness, $l$, which is to say, it does not depend on the liquid flow rate or packing geometry (except as it determines surface area). Cussler calls this "one of the most charming results in engineering." This will allow us to calculate some properties of the solution without reference to a particular packing material and flow rate. Let's also note here that the "enhancement factor", $E$, that comes up frequently in the literature is the ratio of $k_{1}$ to the diffusion-based mass transfer coefficient, which is the coefficient we would have with no chemical reaction. By film theory, the diffusionbased coefficient is what we just mentioned above, giving:

$$
E=\frac{k_{1}}{D_{\mathrm{CO}_{2}} / l}
$$

Now let $\left[\mathrm{CO}_{2}(\mathrm{aq})\right]_{i}=P_{\mathrm{CO}_{2}} H_{\text {app }}$ denote the $\mathrm{CO}_{2}$ concentration on the liquid side at the interface and let $P_{\mathrm{CO}_{2}}^{*} \approx 0$, which is tantamount to our previous assumption that the reverse of reaction 3 is negligible. The concentration profile for a system described by Equation 9 is then (Cussler, 1984):

$$
\frac{\left[\mathrm{CO}_{2}(\mathrm{aq})\right]}{\left[\mathrm{CO}_{2}(\mathrm{aq})\right]_{i}}=\frac{\sinh \left(\sqrt{k_{1} / D_{\mathrm{CO}_{2}}}(l-z)\right)}{\sinh \left(\sqrt{k_{1} / D_{\mathrm{CO}_{2}}} l\right)}
$$

where $z$ is the distance from the interface. For a fast reaction, this can be approximated by a simple 


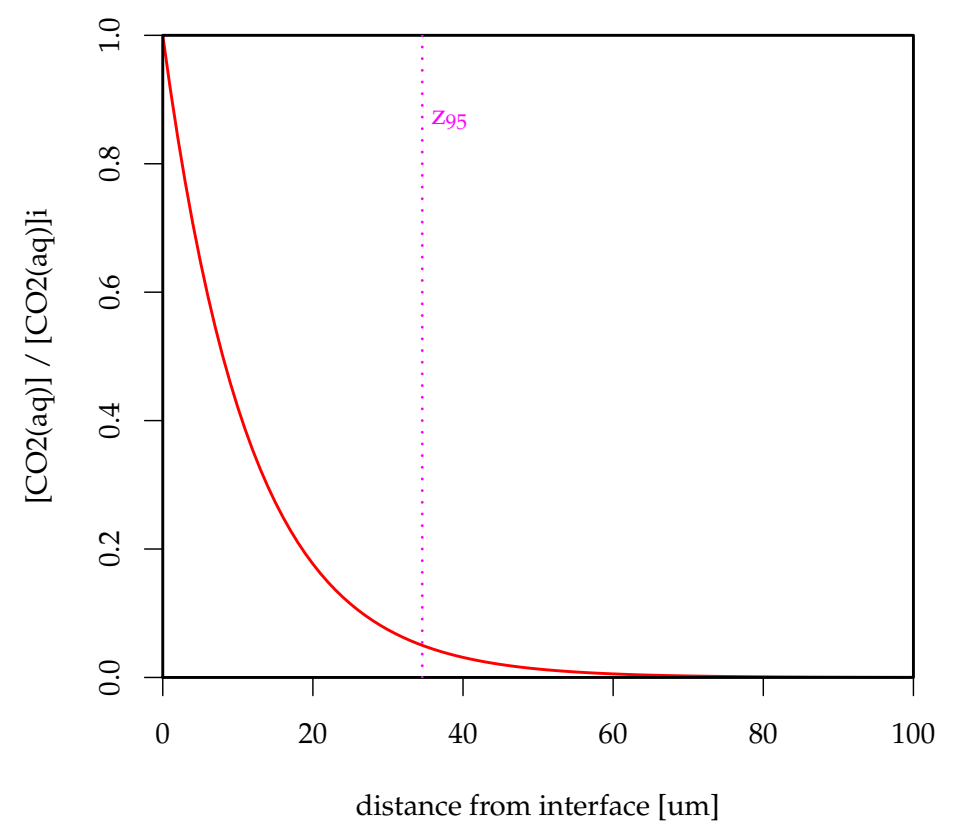

Figure 9: Concentration of $\mathrm{CO}_{2}(\mathrm{aq})$ near the gas/liquid interface for a carbonate solution with $\mathrm{pH} 10$ at $40^{\circ} \mathrm{C}$ and viscosity of $30 \mathrm{wt} \% \mathrm{~K}_{2} \mathrm{CO}_{3} . z_{95}$ denotes the depth at which $95 \%$ of the mass lies above.

exponential:

$$
\frac{\left[\mathrm{CO}_{2}(\mathrm{aq})\right]}{\left[\mathrm{CO}_{2}(\mathrm{aq})\right]_{i}}=\exp \left(-\sqrt{\frac{k_{1}}{D_{\mathrm{CO}_{2}}}} z\right)
$$

Figure 9 shows this concentration profile for a solution with $\mathrm{pH} 10$ at $40^{\circ} \mathrm{C}$. If we are interested in placing a catalyst specifically near the interface, then such a curve illustrates where the catalyst will be active. To quantify, let us define the "penetration depth" as the distance from the interface such that $95 \%$ of $\mathrm{CO}_{2}(\mathrm{aq})$ resides above this depth in a film at steady state. By integrating and normalizing Equation 11, we can find the cumulative fraction of $\mathrm{CO}_{2}(\mathrm{aq})$ as a function of $z$, then we find the penetration depth, denoted $z_{95}$, by setting the fraction equal to 0.95 :

$$
\begin{aligned}
& \text { cumulative fraction }=\frac{\int_{0}^{z} e^{-z \sqrt{k_{1} / D_{\mathrm{CO}_{2}}}} d z}{\int_{0}^{\infty} e^{-z \sqrt{k_{1} / D_{\mathrm{CO}_{2}}}} d z} \\
& =\frac{\sqrt{D_{\mathrm{CO}_{2}} / k_{1}}\left(1-e^{-z \sqrt{k_{1} / D_{\mathrm{CO}_{2}}}}\right)}{\lim _{a \rightarrow \infty} \sqrt{D_{\mathrm{CO}_{2}} / k_{1}}\left(1-e^{-a \sqrt{k_{1} / D_{\mathrm{CO}_{2}}}}\right)} \\
& =1-e^{-z \sqrt{k_{1} / D_{\mathrm{CO}_{2}}}}=0.95 \\
& \Longrightarrow z_{95}=-\sqrt{\frac{D_{\mathrm{CO}_{2}}}{k_{1}}} \ln (1-0.95)=3.0 \cdot \sqrt{\frac{D_{\mathrm{CO}_{2}}}{k_{1}}}
\end{aligned}
$$

The diffusivity is a function of temperature and solution composition. Diffusivity of $\mathrm{CO}_{2}$ in pure water is given by (Cullinane and Rochelle, 2004):

$$
D_{\mathrm{CO}_{2}}=2.35 \times 10^{-6} e^{-2119 / T}
$$

with $T$ in $\mathrm{K}$ and $D_{\mathrm{CO}_{2}}$ in $\mathrm{m}^{2} / \mathrm{s}$. Diffusivity in a concentrated solution can then be approximated by the Stokes-Einstein relation, which states that diffusivity is inversely proportional to viscosity. Knuutila et al. (2010c) give the viscosity relative to pure water of carbonate solutions over a range of concentrations. Figure 


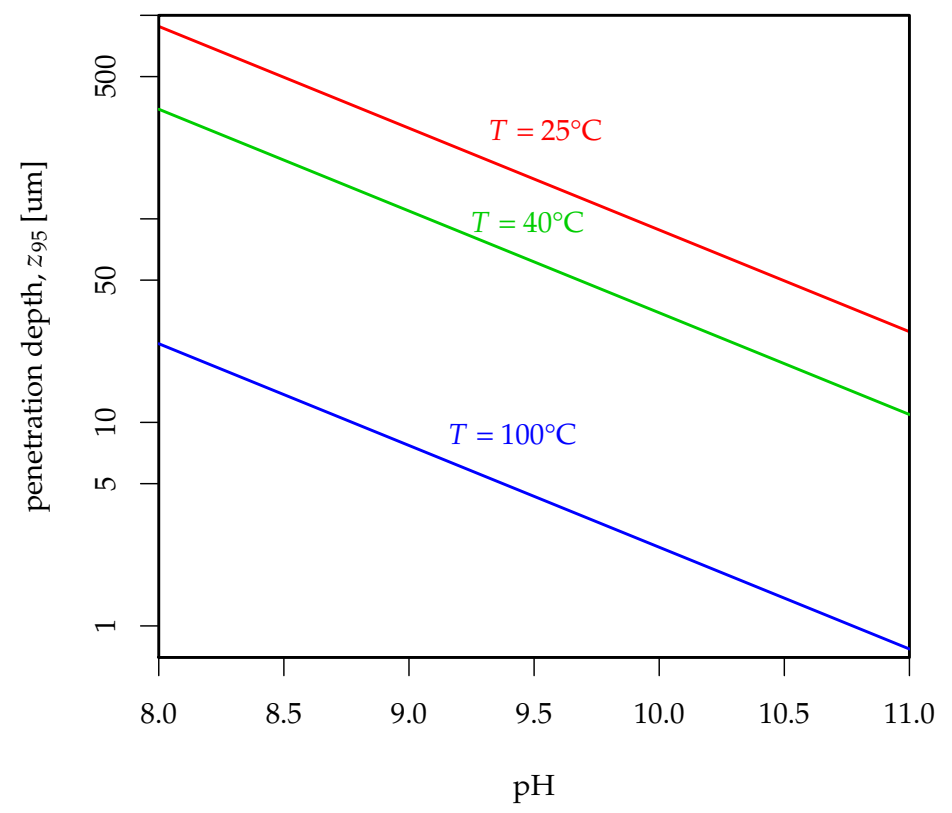

Figure 10: Penetration depth, $z_{95}$, of $\left[\mathrm{CO}_{2}(\mathrm{aq})\right]$ in a carbonate solution as a function of $\mathrm{pH}$ at several temperatures. The viscosity was assumed to be 2.2 times that of water at the given temperature, roughly that of a $30 \mathrm{wt} \% \mathrm{~K}_{2} \mathrm{CO}_{3}$ solution.

10 plots the penetration depth as a function of $\mathrm{pH}$ for several temperatures, assuming the viscosity of a 30 wt $\% \mathrm{~K}_{2} \mathrm{CO}_{3}$ solution, about 2.2 times that of water.

The results shown in Figure 10 are for an uncatalyzed solution; addition of a catalyst will, of course, change the penetration depth. We can consider the penetration depth in a catalyzed solution by assuming the catalyst is homogeneously distributed, at least to the penetration depth. In the case of a catalyst tethered to the surface, the concentration of interest is the effective local concentration in the layer $z<z_{95}$, which may be considerably greater than the bulk concentration. Then we can replace $k_{1}$ with $k_{1, \text { cat }}$ in Equation 12 and the penetration depth follows the pseudo-first-order rate constant as $z_{95} \propto k_{1, \text { cat }}^{-1 / 2}$. So, for example, a catalyst that speeds the reaction by 100 times will reduce the penetration depth by a factor of 10 .

Suppose we have a catalyst of sufficient rate and concentration that it dominates the conversion of $\mathrm{CO}_{2}(\mathrm{aq})$ over the simple reaction with $\mathrm{OH}^{-}$. That is to say, suppose the concentration falls somewhat above the line on Figure 8 for the corresponding $k_{\text {cat }}$ over the working $\mathrm{pH}$ range of the solution. Also suppose the $\mathrm{p} K_{a}$ of the catalyst is low compared with the $\mathrm{pH}$ of the loaded solution. In this case, which is our preferred set of circumstances, the penetration depth is essentially independent of $\mathrm{pH}$. Thus cutting back on a variable, we can plot the penetration depth as a function of catalyst concentration; see Figure 11 . One way to interpret the chart is this: for a tethered catalyst of a given $k_{\text {cat }}$ and solubility, this is the minimum depth we would wish the catalyst to mix well through.

We can also consider, in a very rough sense, what happens if all the catalyst is bound to the very surface, although many of our assumptions will break down as we a approach this physical limit. Suppose we achieve some maximum surface concentration, with the catalyst forming a mono-layer, and giving an effective "concentration" of $20 \mathrm{M}$, which is to say, nearly half as many catalyst molecules at the surface as there are water molecules on the surface of pure water. If we extend the line on Figure 11 for, say, $k_{\text {cat }}=10^{4}$ to $20 \mathrm{M}$, we get a penetration depth of $240 \mathrm{~nm}$. This implies that, even with the catalyst packed as densely as physically possible, we would need a layer at least hundreds of molecules thick to "catch" all the $\mathrm{CO}_{2}$ coming in. Thus, in the case of a mono-layer, the total number of molecules seems to be a more instructive limit than the concentration.

Ignoring the special orientation of water molecules at the surface, the number of molecules per unit surface area in pure water is $1.7 \times 10^{-5} \frac{\mathrm{mol}}{\mathrm{m}^{2}}$ (derived simply from $55 \mathrm{~mol} / \mathrm{L}$ ). Keeping with the $20 \mathrm{M}$ ratio above, 


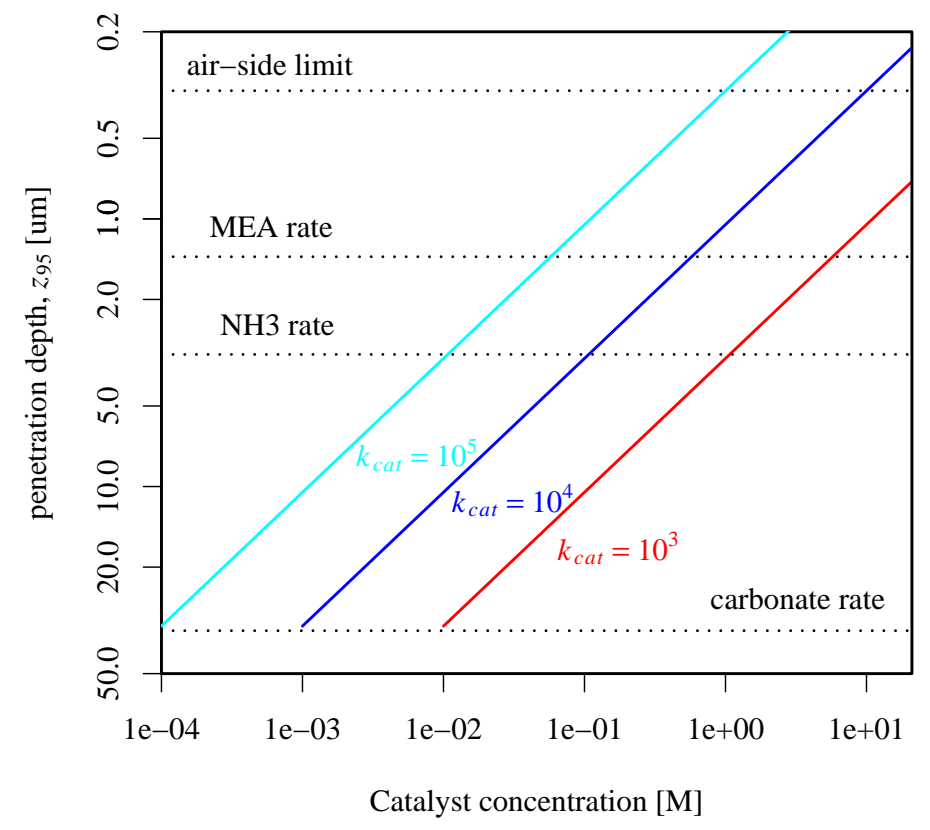

Figure 11: Penetration depth, $z_{95}$, for catalyzed solutions as a function of catalyst concentration for several values of the catalyst reaction constant, $k_{\text {cat }}[\mathrm{L} /(\mathrm{mol} \cdot \mathrm{s})] . T=40^{\circ} \mathrm{C}$ and viscosity consistent with Figures 9 and 10. "Carbonate rate" is the penetration depth for an uncatalyzed solution at $\mathrm{pH} 10$ and $40^{\circ} \mathrm{C}$. "MEA rate" and "NH3 rate" are typical penetration depths for those solvents. "Air side limit" is the penetration depth corresponding to the reaction rate at which gas-side mass transfer begins to dominate in a typical amine-based packed tower. 
suppose a mono-layer of catalyst achieves a surface concentration, which we will denote $S_{c}$, of $6 \times 10^{-6} \frac{\mathrm{mol}}{\mathrm{m}^{2}}$. Again, many of the assumptions of our mass transfer model break down in this limit, probably including the validity of any $k_{\text {cat }}$ measurements, but just for a sense of scale, suppose that the catalyst behaves as if in a homogeneous solution with $\left[\mathrm{CO}_{2}(\mathrm{aq})\right]$ in equilibrium with the gas phase. With those assumptions, we can represent the flux of $\mathrm{CO}_{2}$ into solution (ignoring the contribution of $\mathrm{OH}^{-}$further below the surface) by:

$$
J_{\mathrm{CO}_{2}, \text { mono-layer }}=k_{\text {cat }} S_{c}\left[\mathrm{CO}_{2}(\mathrm{aq})\right]_{i}
$$

Compare this with the flux to a homogeneous catalyzed solution (with our various simplifying assumptions) from above, which we can represent by:

$$
J_{\mathrm{CO}_{2}}=\sqrt{D_{\mathrm{CO}_{2}} k_{c a t}[\mathrm{Cat}]}\left[\mathrm{CO}_{2}(\mathrm{aq})\right]_{i}
$$

Suppose we had two catalysts with the same $k_{c a t}$, one which sticks right to the surface and forms a mono-layer, and the other which dissolves homogeneously. By equating the two fluxes above, we can find the homogeneous concentration that gives equivalent mass transfer to a mono-layer:

$$
\begin{aligned}
k_{c a t} S_{c}\left[\mathrm{CO}_{2}(\mathrm{aq})\right]_{i} & =\sqrt{D_{\mathrm{CO}_{2}} k_{c a t}[\mathrm{Cat}]}\left[\mathrm{CO}_{2}(\mathrm{aq})\right]_{i} \\
\Longrightarrow[\mathrm{Cat}] & =\frac{k_{c a t} S_{c}^{2}}{D_{\mathrm{CO}_{2}}}
\end{aligned}
$$

Now we can plug in some numbers. Taking $S_{c}$ from above, $D_{\mathrm{CO}_{2}}=1.2 \times 10^{-9} \frac{\mathrm{m}^{2}}{\mathrm{~s}}$ (for a $30 \% \mathrm{~K}_{2} \mathrm{CO}_{3}$ solution at $40^{\circ} \mathrm{C}$ ), and, for example, $k_{c a t}=10^{4} \frac{\mathrm{L}}{\mathrm{mol} \cdot \mathrm{s}}$, we get the equivalent homogeneous concentration (after harmonizing the units) is [Cat] $=3 \times 10^{-4} \mathrm{M}$. Which is not very much. This result is perhaps counterintuitive, since it seems the catalyst should be most effective right at the interface. And that is true; given a fixed number of molecules, they are best distributed as close to the interface as possible (in our model). However, the competing effect is that a mono-layer is just not that many molecules. Given the limits of physical space at the interface, it is better to distribute the catalyst throughout the penetration depth.

It is interesting to note that mass transfer to a mono-layer is first order with $k_{c a t}$, whereas for a dissolved catalyst the rate of mass transfer follows $k_{c a t}^{1 / 2}$. Thus, for a sufficiently fast catalyst, a mono-layer is better. The crossover point depends on the solubility limit of dissolved catalyst. If the dissolved catalyst is soluble to $1 \mathrm{M}$, then the rate at which a mono-layer becomes better is above $10^{7} \frac{\mathrm{L}}{\mathrm{mol} \cdot \mathrm{s}}$, which is probably out of the realm of our consideration.

\section{Discussion}

The above calculations should provide reasonable guidance about the required concentration, rate, and placement of catalysts in carbonate solutions. They should also provide some benchmarks to compare with whetted-wall experiments on lean solutions. The next logical step in mass-transfer modeling is probably a reaction-coupled finite element model, such as created by Puxty and Rowland (2011). Such a model can take into account reverse reactions and competing reaction pathways, which will allow accurate handling of absorption in rich solutions and desorption in the stripper, if desired (the kinetics of stripping are given much less attention in the literature, presumably because reactions at the higher stripping temperature are fast enough to be unimportant). A finite element model will also be able to analyze cases where a tethered catalyst has a concentration gradient near the surface. An important input, either for a finite element model or a more-accurate version of the above calculation, will be an activity coefficient for the catalyst. We should work on a way to calculate or measure this.

This paper did not directly address the question of whether capture with carbonate solutions is a good idea. That question hinges largely on the energy efficiency of a carbonate-based capture process. Energy efficiency of carbonates compared with other solvents is the subject of a separate planned analysis, which will be based on equilibrium more than kinetics. The literature reviewed in the Background section does provide some guide to the viability of carbonate-based capture, but I would consider it inconclusive.

Still, we have two reasons to be hopeful that our current efforts are a good match to carbonates: (1) catalysts can address the slow kinetics of carbonate solutions, which is the most-cited drawback of carbonate solutions for carbon capture. Of course, other promoters have been used to solve the kinetic problem. Amine promoters, however, change the VLE properties of carbonate solutions. For example, Cullinane and Rochelle (2004) find that "The addition of $0.6 \mathrm{~m}$ piperazine to a $20 \mathrm{wt} \%$ potassium carbonate system decreases the 
$\mathrm{CO}_{2}$ equilibrium partial pressure by approximately $85 \%$ at intermediate $\mathrm{CO}_{2}$ loading [and] ... increases the heat of absorption from 3.7 to $10 \mathrm{kcal} / \mathrm{mol}$." So, perhaps the catalyst is best-viewed as a way to speed the kinetics of carbonates without changing their VLE characteristics. We also must confirm that that is true. If only by virtue of being an acid, the catalyst may change the VLE characteristics. (2) Encapsulation can provide a viable system design that allows for precipitates. Higher concentrations of carbonates could be used which, in turn, have higher capacity for $\mathrm{CO}_{2}$ and improve overall energy efficiency. Low capacity is often cited as a drawback of carbonates for carbon capture. With one or both of our contributions, carbonate solutions seem to be a promising approach to carbon capture that, if not vastly better than MEA in energy terms, may be much better in terms of environmental impact and scalability.

\section{References}

Abanades, J. C., Rubin, E. S., and Anthony, E. J. (2004). Sorbent cost and performance in CO2 capture systems. Industrial \&5 Engineering Chemistry Research, 43(13):3462-3466.

Astarita, G., Savage, D. W., and Bisio, A. (1983). Gas Treating with Chemical Solvents. John Wiley \& Sons, New York.

Chapel, D. G. and Mariz, C. L. (1999). Recovery of CO2 from flue gases: Commercial trends. In Canadian Society of Chemical Engineers annual meeting, October 4-6, Saskatoon, Saskatchewan, Canada.

Correla, R. J. and Kestlin, J. (1980). Viscosity and density of aqueous na2co3 and k2c03 solutions in the temperature range 20-90 c and the pressure range 0-30 mpa. Journal of Chemical Engineering Data, 25:201-206.

Cullinane, J. T. and Rochelle, G. T. (2004). Carbon dioxide absorption with aqueous potassium carbonate promoted by piperazine. Chemical Engineering Science, 59(17):3619-3630.

Cussler, E. L. (1984). Diffusion: Mass transfer in fluid systems. Cambridge.

Ellis, A. J. (1959). The system Na2CO3-NaHCO3-CO2-H2O at temperatures up to 200c. American Journal of Science, 257:287-296.

Hershey, J. P., Sotolongo, S., and Millero, F. J. (1983). Densities and compressibilities of aqueous sodium carbonate and bicarbonate from 0 to $45^{\circ}$ C. Journal of Solution Chemistry, 12:233-254. 10.1007/BF00646199.

Kamps, A. P.-S., Meyer, E., Rumpf, B., and Maurer, G. (2007). Solubility of CO2 in aqueous solutions of $\mathrm{kcl}$ and in aqueous solutions of k2co3. Journal of Chemical \&3 Engineering Data, 52(3):817-832.

Knovel (2008). Knovel critical tables (2nd edition). online.

Knuutila, H., Hessen, E. T., Kim, I., Haug-Warberg, T., and Svendsen, H. F. (2010a). Vapor-liquid equilibrium in the sodium carbonate-sodium bicarbonate-water-CO2-system. Chemical Engineering Science, 65(6):2218 - 2226 .

Knuutila, H., Juliussen, O., and Svendsen, H. F. (2010b). Density and n2o solubility of sodium and potassium carbonate solutions in the temperature range 25 to $80{ }^{\circ}$ c. Chemical Engineering Science, 65(6):2177 2182.

Knuutila, H., Juliussen, O., and Svendsen, H. F. (2010c). Kinetics of the reaction of carbon dioxide with aqueous sodium and potassium carbonate solutions. Chemical Engineering Science, 65(23):6077 - 6088.

Knuutila, H., Svendsen, H. F., and Anttila, M. (2009a). CO2 capture from coal-fired power plants based on sodium carbonate slurry; a systems feasibility and sensitivity study. International Journal of Greenhouse Gas Control, 3:143-151.

Knuutila, H., Svendsen, H. F., and Juliussen, O. (2009b). Kinetics of carbonate based CO2 capture systems. Energy Procedia, 1(1):1011 - 1018. Greenhouse Gas Control Technologies 9, Proceedings of the 9th International Conference on Greenhouse Gas Control Technologies (GHGT-9), 16-20 November 2008, Washington DC, USA. 
Kohl, A. L. and Nielsen, R. B. (1997). Gas Purification (5th Edition), chapter Chapter 5: Alkaline Salt Solutions for Acid Gas Removal, pages 330-373. Elsevier.

Kothandaraman, A., Nord, L., Bolland, O., Herzog, H. J., and McRae, G. J. (2009). Comparison of solvents for post-combustion capture of CO2 by chemical absorption. Energy Procedia, 1(1):1373 - 1380. Greenhouse Gas Control Technologies 9, Proceedings of the 9th International Conference on Greenhouse Gas Control Technologies (GHGT-9), 16-20 November 2008, Washington DC, USA.

Lee, S. and Kim, J. (2007). Dry potassium-based sorbents for co\&lt;sub\&gt;2\&lt;/sub\&gt; capture. Catalysis Surveys from Asia, 11(4):171-185.

Liang, Y., Harrison, D. P., Gupta, R. P., Green, D. A., and McMichael, W. J. (2004). Carbon dioxide capture using dry sodium-based sorbents. Energy \& Fuels, 18(2):569-575.

Lu, Y., Ye, X., Zhang, Z., Khodayari, A., and Djukadi, T. (2011). Development of a carbonate absorptionbased process for post-combustion $\mathrm{CO} 2$ capture: the role of biocatalyst to promote $\mathrm{CO} 2$ absorption rate. Energy Procedia, 4:1286-1293.

Nelson, T. O., Coleman, L. J., Green, D. A., and Gupta, R. P. (2009). The dry carbonate process: Carbon dioxide recovery from power plant flue gas. Energy Procedia, 1(1):1305 - 1311. Greenhouse Gas Control Technologies 9, Proceedings of the 9th International Conference on Greenhouse Gas Control Technologies (GHGT-9), 16-20 November 2008, Washington DC, USA.

Oyenekan, B. A. and Rochelle, G. T. (2006). Energy performance of stripper configurations for CO2 capture by aqueous amines. Industrial \& Engineering Chemistry Research, 45(8):2457-2464.

Poling, B. E., Thomson, G. H., Friend, D. G., Rowley, R. L., and Wilding, W. V. (2008). Perry's Chemical Engineer's Handbook (8th Edition), chapter Section 2: Physical and Chemical Data, pages 2-1-2-202. McGraw-Hill.

Puxty, G. and Rowland, R. (2011). Modeling CO2 mass transfer in amine mixtures: Pz-amp and pz-mdea. Environmental Science and Technology, 45:2398-2405.

Tosh, J. S., Field, J. H., Benson, H. E., and Haynes, W. P. (1959). Equilibrium study of the system potassium carbonate, potassium bicarbonate, carbon dioxide, and water. Technical report, US Department of the Interior, Bureau of Mines. Report of Investigations 5484.

van der Lee, J. (1998). Thermodynamic and mathematical concepts of chess. Technical report, Ecole des Mines de Paris, Centre d'Informatique Geologique.

Wappel, D., Khan, A., Shallcross, D., Joswig, S., Kentish, S., and Stevens, G. (2009). The effect of SO2 on CO2 absorption in an aqueous potassium carbonate solvent. Energy Procedia, 1(1):125 - 131. Greenhouse Gas Control Technologies 9, Proceedings of the 9th International Conference on Greenhouse Gas Control Technologies (GHGT-9), 16-20 November 2008, Washington DC, USA.

Woolery, T. (1992). A software package for geochemical modelling of aqueous systems: package overview and installation guide (version 7.0). Technical report, Lawrence Livermore National Laboratory. UCRLMA-110662 PT.

Zhang, X. and van Eldik, R. (1995). A functional model for carbonic anhydrase: Thermodynamic and kinetic study of tetreeazcyclododecane complex of zinc(ii). Inorganic Chemistry, 34:5606-5614.

Zhao, C., Chen, X., and Zhao, C. (2009). CO2 absorption using dry potassium-based sorbents with different supports. Energy \& Fuels, 23(9):4683-4687. 